\title{
Visual form recognition threshold and the psychological refractory period ${ }^{1}$
}

\author{
R. RANDOLPH BLAKE ${ }^{2}$ AND ROBERT FOX \\ VANDERBILT UNIVERSITY
}

Two experiments studied the effect of a reaction time response $(R T)$ on visual form recognition threshold when the temporal interval separating the $R T$ stimulus and the recognition stimulus was short. In Experiment 1 an initial $R T$ response to an auditory signal did not impair the subsequent forced-choice visual form recognition threshold. Interstimulus intervals (ISI) of 0, 50, 100, 150, and $200 \mathrm{msec}$ were used; $S$ was always aware of the ISI under test. In Experiment 2 a visual stimulus was used to elicit the RT response; this shift to an intramodal stimulus did not alter the recognition threshold. These data were interpreted as supporting the hypothesis that two stimulus events can be processed simultaneously even when the temporal interval between them is short.

When man is required to process and to respond to two separate inputs arriving closely in time, the response to the second input is usually delayed if the interval between the two inputs is short. This widely replicated phenomenon is referred to as the psychological refractory period (PRP), and it is one aspect of the general problem of information processing in perceptual systems. Studies investigating the PRP have typically used reaction time (RT) as the response. The recent review by Smith (1967) examines the bulk of the data and theory related to the PRP.

The theoretical interpretation which appears to offer the most adequate account of the PRP phenomenon is some version of Welford's (1952) single-channel theory. The general assumption of this model is that because of limited-channel capacity incoming information must be handled sequentially; i.e., if a second stimulus (S2) arrives before the first stimulus (S1) has reached a certain point in processing, then S2 must be held in store until the channel is clear. It is this delay in the initiation of processing S2 that causes the delay in RT. This prolonged RT to $S 2$ is present even when $S$ knows beforehand the order of occurrence of the two signals and, further, knows the temporal interval between the two signals (Bernstein, Blake, \& Hughes, 1968).

Given the general notion of single-channel processing, a next step is to specify the location of the limited channel within the overall processing system. If the information processing system is organized sequentially in several discrete stages, then the locus of the limited channel could be in any one or all of the stages. For example, the locus could be in the stimulus analyzer stage, the response selection stage, or both (Smith, 1967).

The ideal experimental situation for testing these alternatives would be to successively remove the load from each of the different stages and note the results. One strategy would be to remove the load imposed on the response selection stage by eliminating the $\mathrm{RT}$ response to $\mathrm{S} 1$. In this paradigm both stimuli still occur and presumably occupy the stimulus analyzer, but a response is required only to S2. Using this method Davis (1959) and Nickerson (1965) found that the delay in RT to $\mathrm{S} 2$ was still present although the delays were not so great as when a response was required to $S 1$.

Since these studies have ostensibly removed the load from the response stage the remaining delay in RT must be attributed to the stimulus analyzer stage. But that interpretation is not unequivocal because in all these studies the ISI was randomly varied. And, as much research on the effects of foreperiod delays on reaction time has indicated, uncertainty concerning the onset of the signal can substantially increase reaction time (e.g., Woodworth \& Schlosberg, 1954; Teichner, 1954). Within the context of a PRP experiment employing reaction time to the S1 and S2 signals, a random ISI sequence alone can produce a significant increase in RT to S2 (e.g., Bernstein et al, 1968).

A second strategy for locating the locus of delay is to remove the load on the stimulus analyzer stage. In a study designed to eliminate the effects of S1, Davis (1965) had S spontaneously elicit the first response (left-hand key depression) which was followed by a stimulus requiring a second response (right-hand key depression). In this situation he found no impairment of the second RT response. Yet it seems likely that a spontaneous response does not really place a load on the response selection stage. If that is so, then clear inferences about the locus of delay cannot be made.

As stated earlier, the immediate response (RT) to S2 has always been used as the indicator of the delay in the central processing mechanism. But the assumptions of a single-channel interpretation allow this model to be extended beyond RT and to include such tasks as form-recognition threshold. Accordingly, if $S$ is required to make an RT to a first signal that is followed close in time by a tachistoscopic recognition task, then at short ISIs the recognition accuracy should be impaired if the $S$ is limited in his capacity to process incoming information. Since the recognition task, unlike RT, will impose no immediate burden on the response selection stage, any degradation in recognition accuracy can be attributed to limitations on the stimulus processing stage. This logic motivated the following experiment, which was designed to load the stimulus analyzer but not the response stage.

\section{EXPERIMENT 1}

Subjects

Three female undergraduates and one male graduate student from Vanderbilt University served for two practice and four experimental sessions of approximately I-h duration. Ss' ages ranged from 20 to 31 . Each $S$ was paid for participation in the project. Only one of the four Ss had previous experience in psychophysical experiments, so proper training was given each $S$ to allow for practice effects. Two of the $S s$ were right-handed and two left-handed.

\section{Apparatus}

S1 was an auditory signal generated by an $8-\mathrm{dB}$ increase of a 500 -cps tone for a duration of $.1 \mathrm{sec}$. The resting intensity was just loud enough to serve as a masking noise for the starter button. The continuous tone was generated by an Eico audio generator and delivered over a set of Koss Headphones. A two-channel tachistoscope (Scientific Prototype, Model 800E) was used to present $\mathrm{S} 2$, which called for a forced-choice recognition task. One of three symmetrical letter forms $(\mathrm{A}, \mathrm{T}$, or $U$ ) appeared in the center of four fixation points rectangularly arranged to form a 2 -deg foveal area. The forms were black Letraset letters which subtended a visual angle of $30 \mathrm{~min}$. They were each mounted on white cards fitted to the stimulus holders for the tachistoscope. The luminance of the 
fixation field, which remained on at all times, was $33 \mathrm{ft}-\mathrm{L}$, and the luminance of the combined fixation and stimulus fields was $36 \mathrm{ft}-\mathrm{L}$, as measured by a Pritchard Spot photometer.

The onset of the auditory stimulus was the cue for S's RT response, which was release of a telegraph key. RT was measured in milliseconds by a Hunter Model 120A Klockounter.

The entire cycle for a single trial was initiated when E pressed a start button which simultaneously started the Hunter clock and delivered the auditory stimulus. The S's key release stopped the clock. The interval (ISI) between the stimuli was controlled by a Hunter Model 100-C decade interval timer.

\section{Procedure}

The first two sessions were used to establish for each $\mathrm{S}$ a stable recognition threshold of $66 \%$ correct recognition. Thresholds were obtained by varying exposure duration. During these sessions Ss also received practice in RTs to the auditory stimulus, but the threshold measurement task and the RT task were never performed concurrently. To compensate for any practice effect, the $66 \%$ threshold was checked before and after each experimental session. The range of exposure durations for threshold values was 18-29 msec.

As mentioned earlier, the auditory signal was designated as $\mathrm{S} 1$ and always preceded the visual stimulus. Five intervals were used to separate the two: $0,50,100,150$, or $200 \mathrm{msec}$. These values were selected because much previous research had indicated that the maximum PRP effect is likely to be found within this range. The $S$ was always aware of which ISI was being used. Each experimental session was divided into five blocks of 42 trials, half of the trials requiring an RT to S1 plus the recognition task, the other half of the trials requiring only the recognition with no RT to S1 even though S1 was still presented. Whether the RT-plus-recognition condition or recognition-alone condition was run first in each ISI block was randomly decided with the stipulation that over the four sessions each condition came first in the block equally often. Before each ISI block S was shown the interval to be used in that block. S was instructed before the RT-plus-recognition trials to react as fast as possible. The intertrial interval was approximately $10 \mathrm{sec}$. The start of each trial was signalled by insertion of the stimulus card holder into the T-scope, an insertion which was clearly audible. In accord with a predetermined, random schedule the $\mathrm{Sl}$ stimulus was presented 1-3 sec after insertion of the card holder.

Thus, within each 1-h session 21 trials (each of the three letters appeared seven times) requiring RT-plus-recognition and 21 requiring recognition alone were obtained at each ISI. In all situations requiring RTs $S$ was allowed to use his dominant hand.

\section{RESULTS}

In Table 1 the percentage of correct recognitions for the RT and the no-RT conditions at each ISI is given. Inspection of these data suggests that the RT did not effect recognition accuracy, a conclusion substantiated by the lack of a main effect for RT in the analysis of variance $(F<1)$.

Analysis of variance revealed a marginally significant effect

Table 1

Percentage of Correct Recognition at Each ISI for RT-Plus-Recognition, and for Recognition-Alone (Audio-Visual)

\begin{tabular}{lccccc}
\hline & \multicolumn{5}{c}{ ISI } \\
\cline { 2 - 6 } & 0 & 50 & 100 & 150 & 200 \\
\cline { 2 - 6 } $\begin{array}{l}\text { RT Plus } \\
\text { Recognition }\end{array}$ & $72 \%$ & $71 \%$ & $74 \%$ & $74 \%$ & $70 \%$ \\
$\begin{array}{l}\text { Recognition } \\
\text { Alone }\end{array}$ & $69 \%$ & $70 \%$ & $78 \%$ & $70 \%$ & $72 \%$ \\
\hline
\end{tabular}

for ISI $[F(4,12)=3.27, p<.05]$, but the Newman-Keu multiple comparison procedure showed that none of the separate ISI means were significantly different from each other. The source of the significant $F$ is most likely an elevation of recognition scores at one ISI interval for the recognition-alone condition. This effect did not appear in the subsequent study (Experiment 2) and is probably due to chance. The significant Ss effect $[F(3,12)=6.57, p<.01]$ was due to the inability to set the recognition level for each $S$ at exactly $66 \%$. Relevant interaction terms were not significant.

The lack of a significant ISI by RT-recognition interaction $(\mathrm{F}<1)$ is of special interest. That is so because with a typical PRP paradigm (S1 - RT1, S2 - RT2) an ISI by RT-condition interaction can be expected if S1 without RTl produced no refractoriness. But with the RT-plus-recognition and recognition-alone design used in these experiments, the opposite expectation is true; i.e., the absence of refractoriness would be reflected in a nonsignificant ISI by RT-condition interaction.

Although the data clearly seem to indicate that recognition accuracy is not impaired by the reaction time task, it is possible that recognition accuracy is preserved at the expense of reaction time performance. That is, Ss may increase their RT in order to make correct recognitions. But the restricted range of RTs (150-159 msec) at each ISI value suggests that this is not the case. Further support is provided by the small correlation $(\mathrm{r}=.025)$ between RT and recognition accuracy at the corresponding ISIs. To determine if the RT to Sl was associated with accuracy of recognition, mean RTs were obtained for trials where $S$ correctly reported the letter present and for trials where $S$ was in error. These two means were $154 \mathrm{msec}$ and $157 \mathrm{msec}$, respectively, and do not differ significantly.

\section{DISCUSSION}

The results suggest that $S$ can process the second of two events without impairment even when it closely follows the first event. A further implication is that the delay in RT to the second stimulus in previous experiments is not entirely due to a limited stimulus-processing channel but to a limitation in the response-selection stage. The present results may be restricted to the case where the two events occur in different modalities (e.g., auditory followed by visual), although data reported by Davis $(1957,1959)$ support the notion that signals from auditory and visual modalities converge onto a common central channel. In order to determine if the difference between the intermodality and intramodality conditions is critical, a second experiment was conducted. In this study both signals occurred in the visual modality.

\section{Subjects}

\section{EXPERIMENT 2}

Three male undergraduates served for two practice and four experimental sessions. The same training procedure was employed as in the first experiment.

\section{Apparatus and Procedure}

Due to the extra visual field needed, a Scientific Prototype Model GA three-channel tachistoscope was used. In this experiment $\mathrm{S} 1$ consisted of four small transilluminated circles (visual angle of $5 \mathrm{~min}$ ). These circles appeared at the corners of an imaginary diamond. The horizontal and vertical distances between the circles were $2 \mathrm{deg} 10 \mathrm{~min}$, thus minimizing interaction with the portion of the field upon which the letter was presented. These circles, which were the signal for the RT, came on when the start button was depressed and remained on for $25 \mathrm{msec}$ at an intensity of $38 \mathrm{ft}-\mathrm{L}$. The three letters (A, T, and $\mathrm{U})$ and the fixation dots were reconstructed so as to maintain the same relative size and visual angle as in 
Experiment 1. The luminance of the fixation field was $28 \mathrm{ft}-\mathrm{L}$ while the recognition-plus-fixation field had a total luminance of $32 \mathrm{ft}-\mathrm{L}$. The same telegraph key-clock arrangement was used. White noise was used to mask the starter button click.

The same procedures as in Experiment 1 were employed.

\section{RESULTS}

The percentage of correct recognitions for the RT and no-RT conditions for each ISI appears in Table 2. The apparent absence of an RT-condition effect is confirmed by analysis of variance $(F<1)$. The main effect of ISI was not significant $(F<1)$. The main effect of Ss was again significant $[F(2,12)=24.96, p<.0001]$. The ISI by RT-condition interaction was not significant $[F(4,6)=1.62, p<.29]$. The mean RT to the first stimulus ranged from 198 to $223 \mathrm{msec}$ over all ISI values. The correlation between RT and recognition accuracy was small and not significant (-.23).

Thus, these results are in close agreement with those from Experiment 1, and support the conclusion that RT to Sl has no effect upon recognition accuracy. Parenthetically, it should be noted that there are good empirical reasons for believing that recognition accuracy should not influence RT to S1. A number of studies, specifically concerned with the retroactive effects of a second response upon the first response, have failed to find any influence upon the first response. This is true for modified choice reaction-time situations (Koplin, Fox, \& Dozier, 1966; Lappin \& Eriksen, 1964) and for situations which reduce the phenomenal brightness of the first signal through metacontrast operations (Fehrer \& Raab, 1962; Harrison \& Fox, 1966; Schiller \& Smith, 1966).

Even though the results of Experiments 1 and 2 reveal no inhibitory effect of RT to the first signal upon recognition accuracy, it is at least logically possible that the absence of an inhibitory PRP effect is not due to the characteristics of the recognition task, but rather is due to some general feature of the experimental situation which would preclude a PRP effect even if an RT response to the second signal was required. But data from an unpublished experiment conducted for another purpose is available which demonstrate that the PRP effect can be obtained with apparatus and procedures highly similar to those used in Experiments 1 and 2. In this experiment, RTs were required to two visual signals separated by five ISI values: $0,25,50,75$, and $100 \mathrm{msec}$. The stimulus for the first signal was the same one used in Experiment 2: four dots of light arranged in a diamond pattern. The stimulus for the second signal was a similar set of dots arranged in a rectangular pattern. The three Ss were practiced and aware of the ISI interval under test. An auditory ready signal preceded a 1-3 sec foreperiod varied in accord with a predetermined random schedule. All Ss exhibited the PRP effect: a nonmonotonic increase in RT to the second stimulus, on the order of $40 \mathrm{msec}$ at ISI intervals of 25,50 , and $75 \mathrm{msec}$. These results provide additional evidence in support of our interpretation of Experiments 1 and 2 .

Table 2

Percentage of Correct Recognition at Each ISI for RT-Plus-Recognition, and for Recognition-Alone (Visual-Visual)

\begin{tabular}{lccccc}
\hline & \multicolumn{5}{c}{ ISI } \\
\cline { 2 - 6 } & 0 & 50 & 100 & 150 & 200 \\
\cline { 2 - 6 } $\begin{array}{l}\text { RT Plus } \\
\begin{array}{l}\text { Recognition } \\
\text { Recognition } \\
\text { Alone }\end{array}\end{array} 59 \%$ & $55 \%$ & $62 \%$ & $66 \%$ & $66 \%$ \\
\hline
\end{tabular}

\section{DISCUSSION}

The results of both studies suggest that two events occurring closely in time can each be processed with no degrading effect on the second. This in turn implies that the delay in RT to S2 found in previous experiments could be due to the response selection stage and not to a single-channel limit on the stimulus-analyzer stage.

One way to account for the absence of recognition threshold impairment is that a briefly exposed form can be temporarily held in storage until the processing stage is free of S1. Yet there is evidence of a steep decay function for stimuli which must be briefly held before processing (Sperling, 1963). If in these experiments the forms were being stored in some short-term memory system, then one would expect more errors at the shorter ISIs due to longer required storage while waiting to be processed. This was not found, suggesting that processing of $S 2$ is initiated immediately whether or not $S 1$ is still being processed.

Though these results alone do not rule out the possibility of sequential sensory processing with a limited channel capacity, they do suggest that the channel restriction is not in the stimulus analyzer portion of the system.

\section{REFERENCES}

BERNSTEIN, I. H., BLAKE, R. R., \& HUGHES, M. H. Effects of time and event uncertainty upon sequential information processing. Perception \& Psychophysics, 1968, 3, 177-184.

DAVIS, R. The role of "attention" in the psychological refractory period. Quarterly Journal of Experimental Psychology, 1959, 11, $211-220$.

DAVIS, R. Expectancy and intermittency. Quarterly Journal of Experimental Psychology, 1965, 17, 75-78.

DAVIS, $R$. The human operator as a single channel information system. Quarterly Journal of Experimental Psychology, 1957, 9, 119-129.

FEHRER, E., \& RAAB, D. Reaction time to stimuli masked by metacontrast. Journal of Experimental Psychology, 1962, 63, 143-147.

HARRISON, K., \& FOX, R. Replication of reaction time to stimuli masked by metacontrast. Journal of Experimental Psychology, 1966, $71,162-163$.

KOPLIN, J. H., FOX, R., \& DOZIER, F. A failure to replicate the inhibitory effects of a second stimulus following the primary stimulus to react. Journal of Experimental Psychology, 1966, 72, 914-916.

LAPPIN, J. S., \& ERIKSEN, C. Inhibition of a simple visual reaction time by a second stimulus: A failure to replicate. Psychonomic Science, 1964, 1, 293-294.

NICKERSON, R. S. Response time to the second of two successive signals as a function of absolute and relative duration of intersignal interval. Perceptual \& Motor Skills, 1965, 21, 3-10.

SCHILLER, P. H., \& SMITH, M. C. Detection in metacontrast. Journal of Experimental Psychology, 1966, 7, 32-39.

SMITH, M. C. Theories of the psychological refractory period. Psychological Bulletin, 1967, 67, 202-213.

SPERLING, G. A model for visual memory tasks. Human Factors, 1963 , $5,19-31$.

TEICHNER, W. H. Recent studies of simple reaction time. Psychological Bulletin, 1954, 51, 128-149.

WELFORD, A. T. The psychological refractory period and the timing of high speed performance: A review and a theory. British Journal of Experimental Psychology, 1952,43, 2-19.

WOODWORTH, R. A., \& SCHLOSBERG, H. Experimental psychology. New York: Holt, Rinehart, and Winston, 1954.

\section{NOTES}

1. This research was supported in part by NIH Grant NB-07619. We thank Pat McGregor for his assistance in gathering data and Ira Bernstein for advice and encouragement.

2. Address: Department of Psychology, Vanderbilt University, Nashville, Tenn. 37203.

(Accepred for publication September 11, 1968.) 